Research Article

Nova Biologica Reperta 8(1): 13-19 (2021)

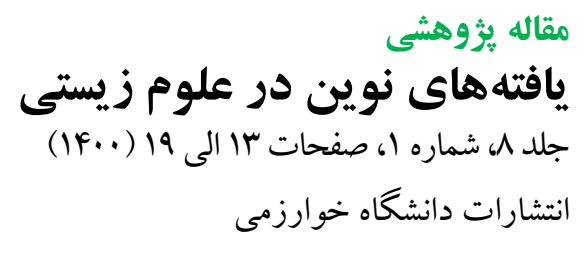

https://nbr.khu.ac.ir; Kharazmi University Press; DOI: 10.29252/nbr.8.1.13

$$
\begin{aligned}
& \text { تاثير بِيتيد آنتاكونيست VEGFB بر ميزان بيان 210-miR در سرطان بستان مدل موشى }
\end{aligned}
$$

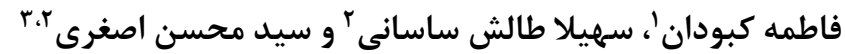

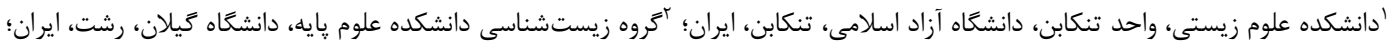

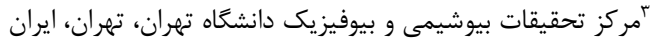

$$
\begin{aligned}
& \text { مسئول مكاتبات: سهيلا طالش ساسانى، sasani@guilan.ac.ir }
\end{aligned}
$$

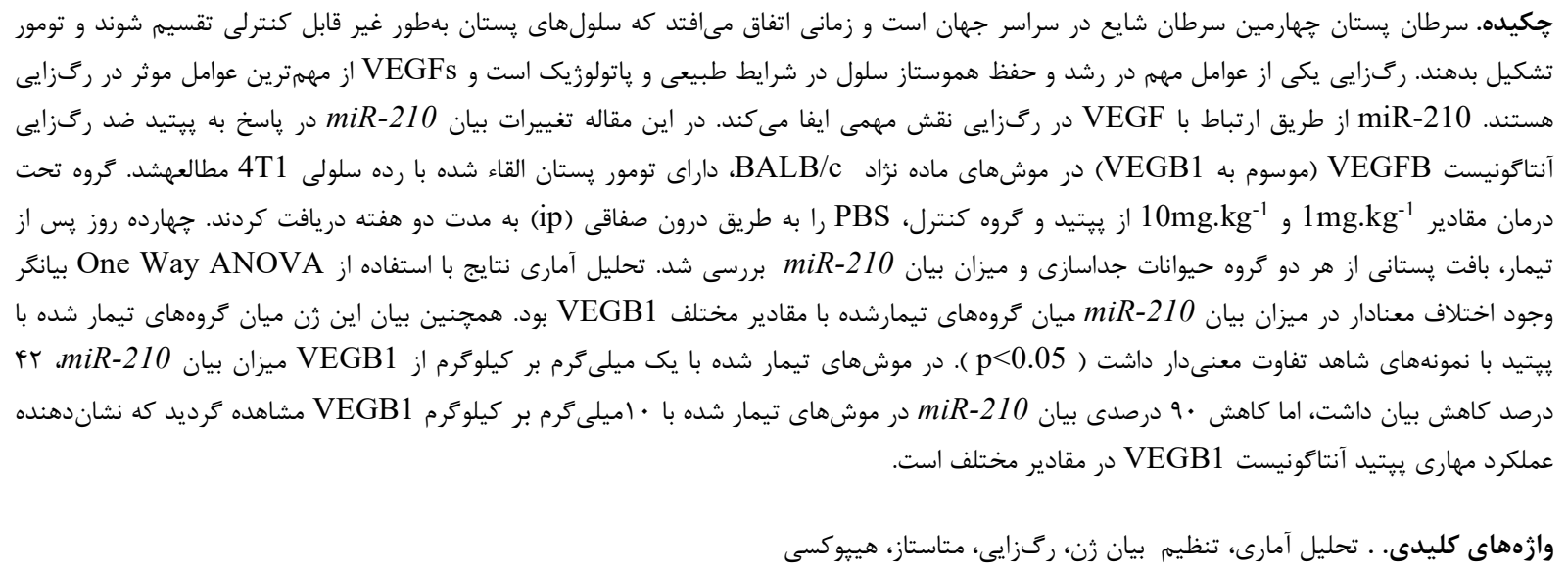

\title{
The effect of a VEGFB antagonist peptide on the expression level of miR-210 in a mouse model of breast cancer
}

\section{Fatemeh Kaboudan ${ }^{1}$, Soheila Talesh Sasani² \& Seyed Mohsen Asgharii,3}

${ }^{1}$ Faculty of Biological Science, Tonekabon Branch, Islamic Azad University, Tonekabon, Iran; ${ }^{2}$ Department of Biology, Faculty of Sciences, University of Guilan, Rasht, Iran; ${ }^{3}$ Iran Institute of Biochemistry and Biophysics (IBB), University of Tehran, Tehran, Iran

Correspondent Author: Soheila Talesh Sasani, sasani@guilan.ac.ir

\begin{abstract}
Breast cancer is the fourth common cancer worldwide and occurs when breast cells begin to uncontrolled division and tumor formation. Angiogenesis is one of the essential factors in cell growth and maintenance of homeostasis in the natural and pathological conditions, while VEGFs are the most critical factors in angiogenesis. MiR210 plays an important role in the angiogenesis via association with VEGF. Here, the miR-210 expression changes in response to a VEGFB antagonist peptide, called VEGB1, was studied in female BALB/c mice bearing 4T1 cell line induced breast tumor. The treated group received $1 \mathrm{mg} \cdot \mathrm{kg}^{-1}$ and $10 \mathrm{mg} \cdot \mathrm{kg}^{-1}$ of the peptide and the control group received PBS intraperitoneally during two weeks. Both of the animal groups underwent a resection of breast tissue 14 days after treatment and miR-210 expression level was investigated. Statistical analysis by On-way ANOVA showed that the expression level of miR-210 gene had significant differences among the groups treated with various doses of VEGB1. Also, the gene expression was significantly different between peptide-treated groups and control samples $(p<0.05)$. MiR-210 expression level had 42\% reduction in mice treated with $1 \mathrm{mg}^{-\mathrm{kg}^{-1}}$ of VEGB1, while $90 \%$ was seen in mice treated with 10mg. $\mathrm{kg}^{-1}$ of VEGB1 showing the inhibitory function of VEGB1 antagonist peptide at different doses.
\end{abstract}

Key words. angiogenesis, regulation of gene expression, hypoxia, metastasis, statistical analysis 
رگزايى تنظيم مى گردد و درصورتى كه اين تعادل از بين برود

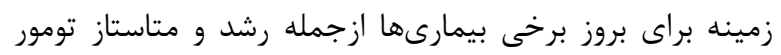
فراهم مىشود (Odorisio et al., 2006).

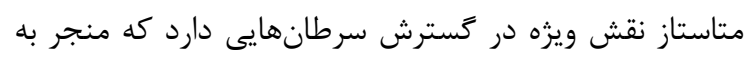

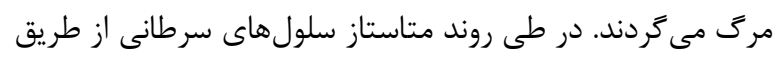

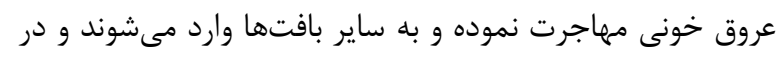

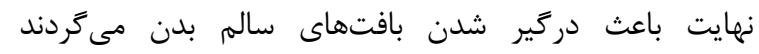

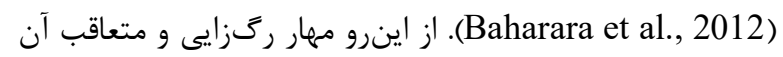

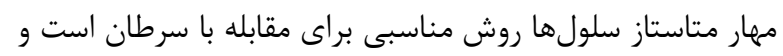

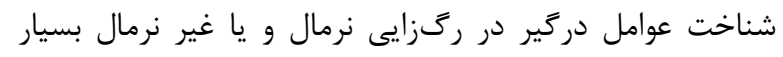

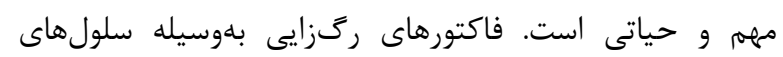

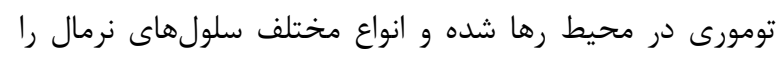

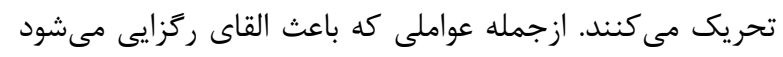

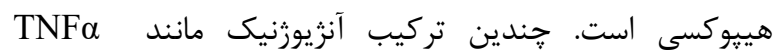
Vascular ) VEGF ،(Tumor Necrosis Factor- $\alpha$ ) Basic ) bFGF , (Endothelial Growth Factor (Fibroblast Growth Factor

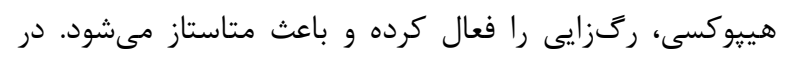

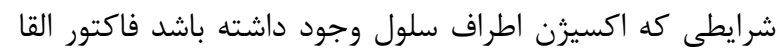

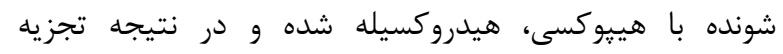

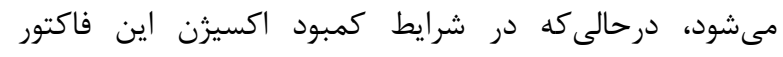

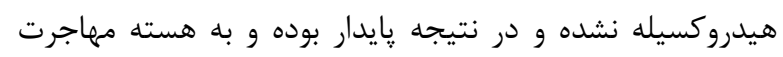

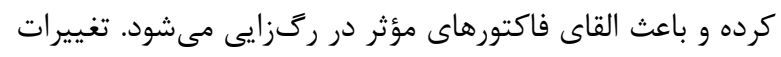

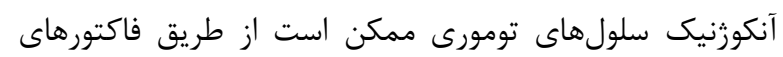

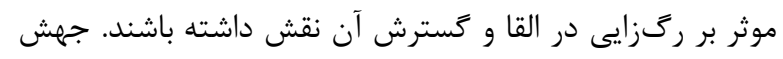

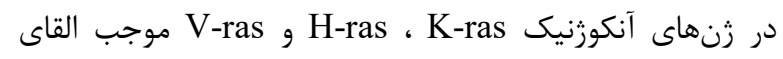

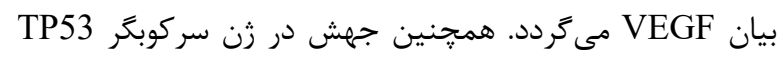
منجر به كاهش توليد TSP-1 و افزايش بيان VEGF

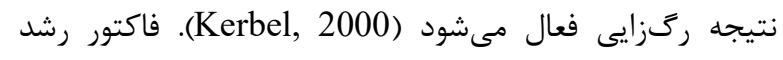

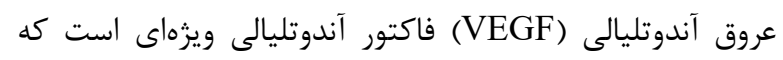

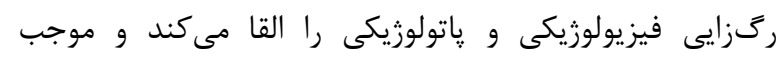
افزايش نفوذيذيرى عروق ميىشود (Leung et al., 1989).

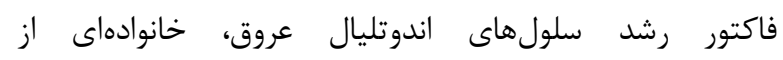

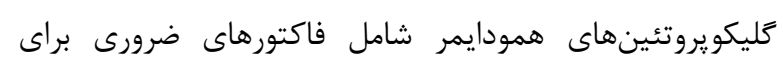

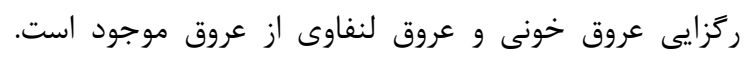
JEGF

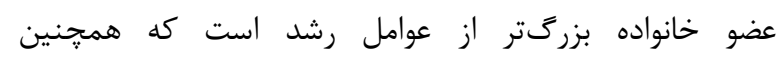

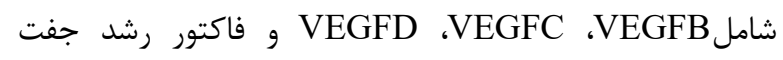

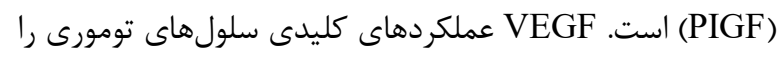
تنظيم مى كند. كزارشهاى اوليه درباره تاثير VEGF
سرطان عمدهترين عامل مرگ مقومير در كشورهاى پيشرفته

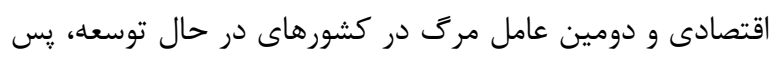
از بيمارىهاى قلبى-عروقى است (Stewart \& Wild, 2014).

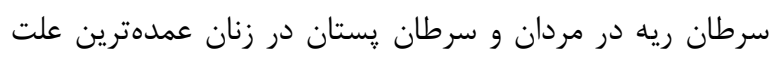

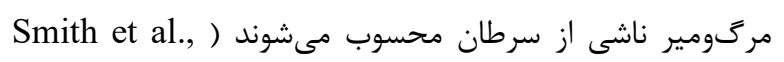

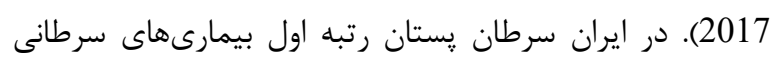

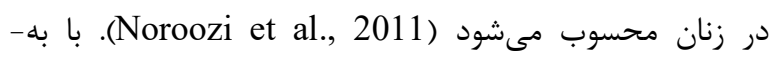

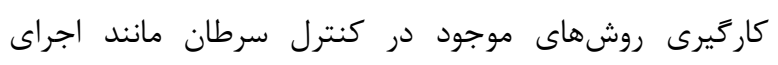

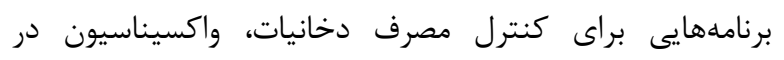

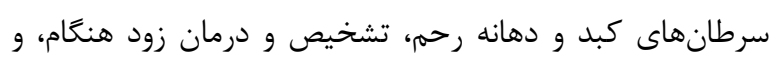

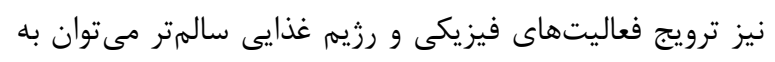

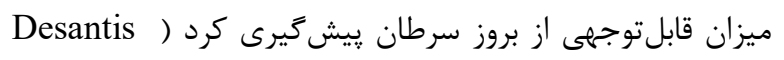
(et al., 2011

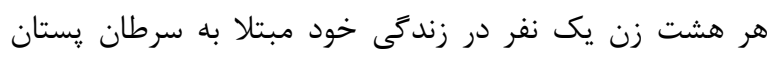

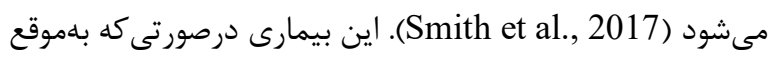

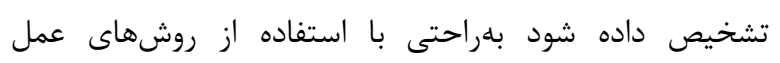

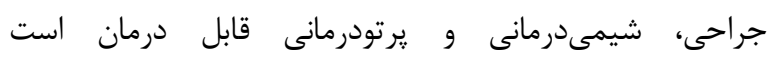

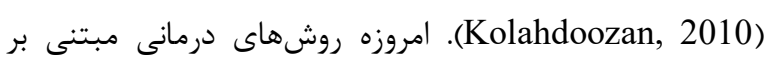

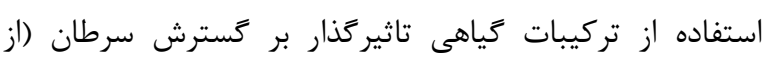

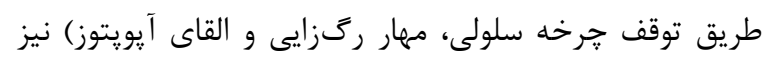
مورد توجه محققين هستند ) (2019 ركَهاى جديد در بزرگسالان از شبكه عروقى جنينى ايجاد

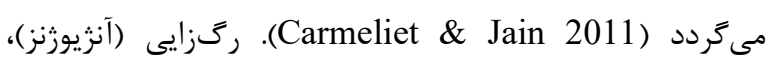

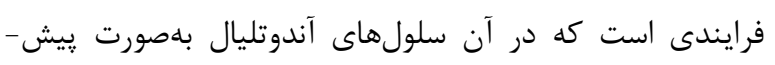

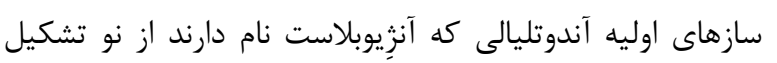

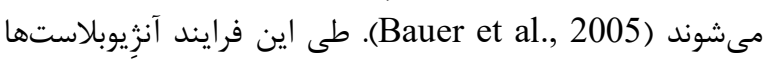
تكثير يافته و با هم ائتلاف كرده ساختارهاى اوليه ركى إنى را ايجاد

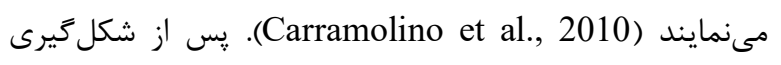

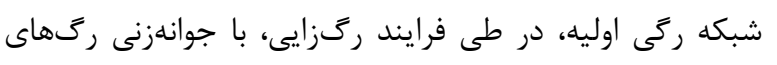

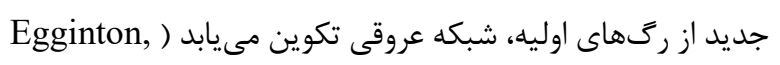

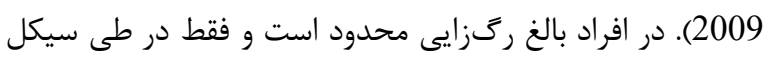

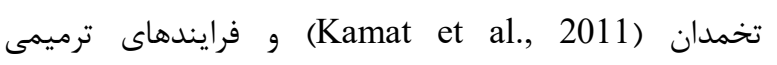

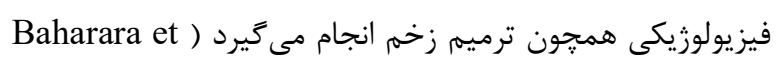

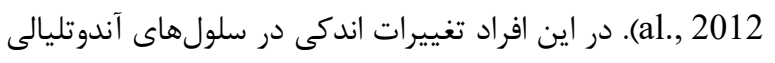

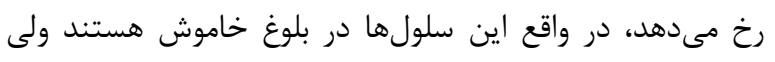

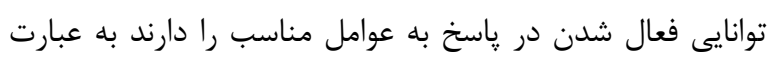

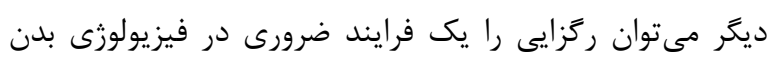

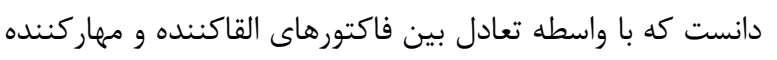


مواد و روش ها در اين مطالعه موشهاى ماده نزاد Balb/c، داراى تومور

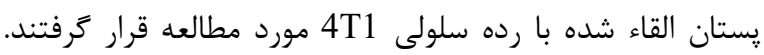

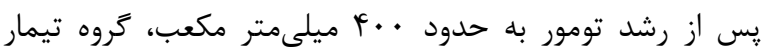

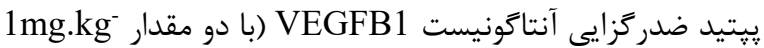

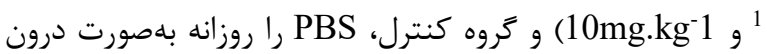
صفاقى (ip) و به مدت دو هفته دريافت كردند. هر زروه شامل r

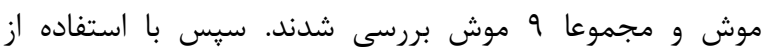

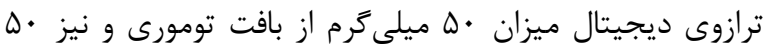
ميلى

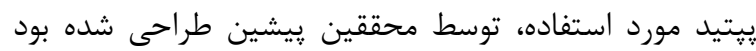

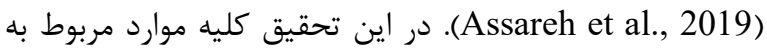
اخلاق كار با حيوانات رعايت گرديد. اين تحقيق داراى شناسه

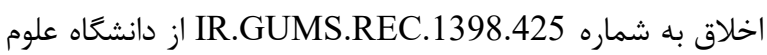
يزشكى گيلان است.

\section{استخراج miRNA و ساخت}

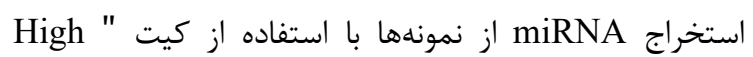
pure miRNA isolation انجام و كميت وكيفيت miRNA به كمك دستگًاه نانودراب و الكتروفورز روى زل آحارز r درصد ارزيابى شد. باقيمانده احتمالى دهي DNA

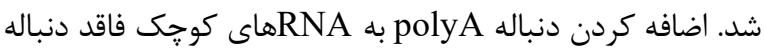

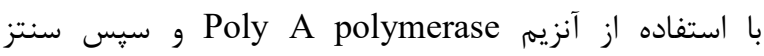
Thermo Fisher Science, " با استفاده از كيت cDNA "USA

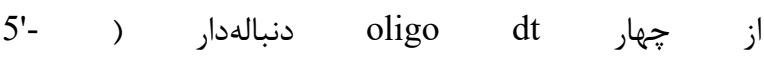
GCGTCGACTAGTACAACTCAAGGTTCTTCCA Ramezani ) استفاده گرديد (GTCACGACG(T)18V-3'

.(et. al., 2020

مطالعه بيان miR-210 به كمك روش Real-time PCR يرايمرهاى اختصاصى براى كنترل داخلى) با استفاده از نرم افزار V.7.54 طراحى شدند. پس از بررسى اختصاصى بودن پرايمرها

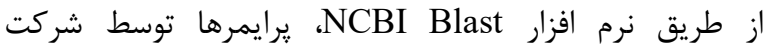
ماكروزن ساخته شدند. مشخصات يرايمرهاى مورد استفاده در

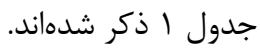
براى اطمينان از صحت مراحل استخراج miRNA، سنتز cDNA

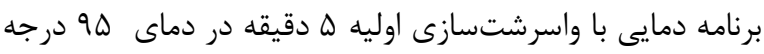

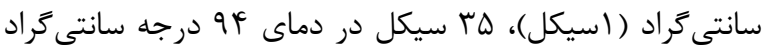

سلولهاى تومورى نشان داد كه مىتواند رشد، بقا و مهاجرت سلولهاى سرطانى را افزايش دهد (Fukasawa et al., 2007). ها ميى توانند هر دو نقش آنكوزنى و سركوبگر تومورى را داشته باشند كه در اين صورت به ترتيب Tumor suppressor miR و خوانده مىشوند. اولين گزارش مربوط به دخالت miRNA در سرطان يستان نشان داد كه عدم تنظيم مناسب qriRNA در در اين بيمارى موثر بودند (Almeida et al., 2011). ميكرو ريبونوكلئيك اسيدها (ميكرو RNA)، ريبونوكلئيك اسيدهاى غيركدكنندهاى هستند

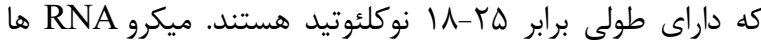
بيان زنها را يس از رونويسى از طريق تجزيه mRNA يا مهار

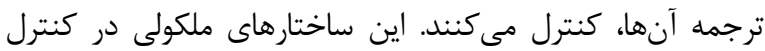
فرايندهاى مختلف فيزيولوزيك و ياتولوزيك سلولى شركت نموده،

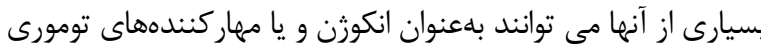

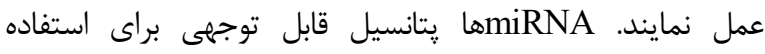

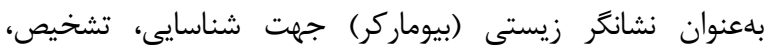
طبقهبندى و درمان سرطان دارند. miRNA علاوهبر تعيين نوع

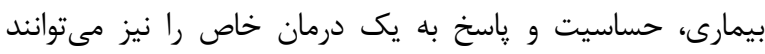
تعيين كنند (Sempere \& Kauppinen, 2009). ثن miRNA-210 در انسان بر روى كروموزوم شماره 11 و در دم:

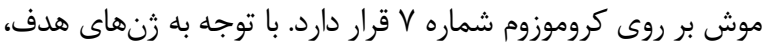

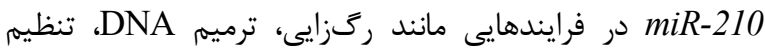

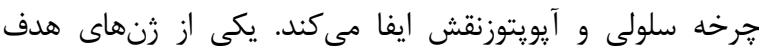
عوامل القا شونده توسط هيبوكسى، miR-210 است. در شرايط هييوكسى HIF-1(Hypoxia) فعال به محل اتصالش در يروموتور زن miR-210 متصل شده و بيان miR-210 را افزايش مىدهد. افزايشmiR-210 موجب تغيير بيان جندين زن دخيل در ياسخهاى سلول به هييوكسى مىشود. يكى از اثرات هييوكسى غلبه بر توقف سيكل سلولى ايجاد شده در اثر هييوكسى

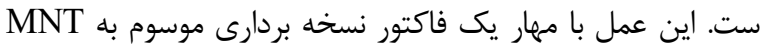
(MAX network transcriptional repressor) همجنين در سرطان گِتان و ملانوما ميزان بيان اين miRNA با

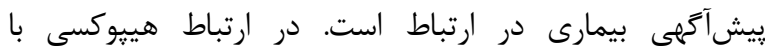

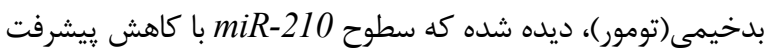
در نمونههاى سرطان يستان و ملانوما مرتبط است ( Bianchi et .(al., 2009

هدف از اين مطالعه بررسى تاثير يֶُتيد ضدرگزايى آنتاگونيست

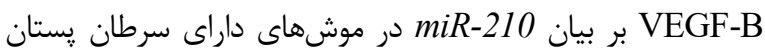

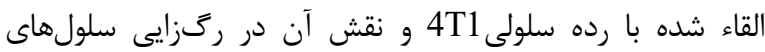
سرطانى است. 


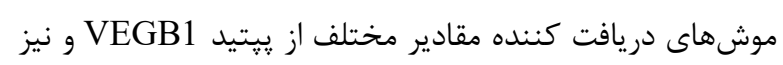

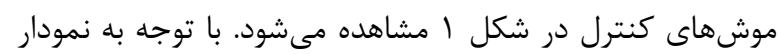

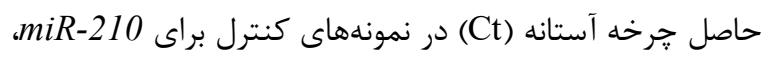

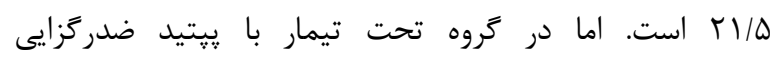

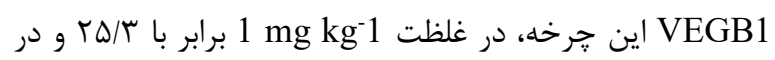
كروه تيمار شده با غلظت

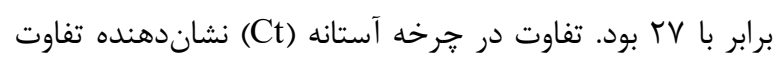

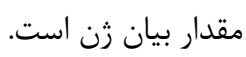

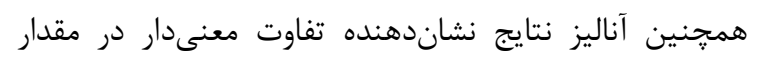

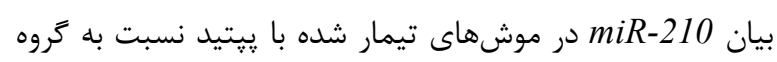

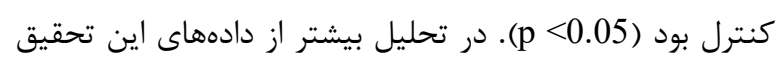

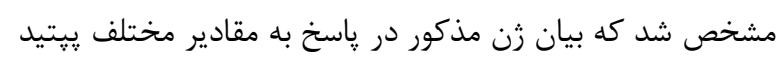

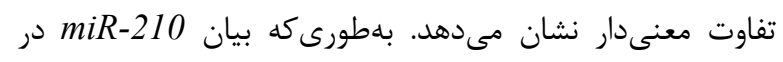

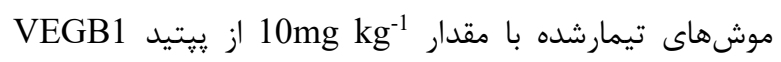

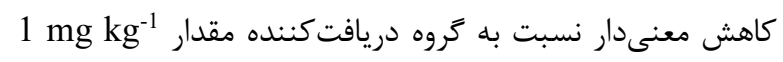

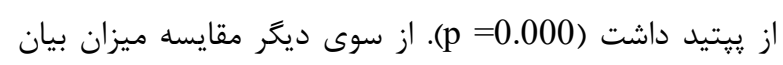

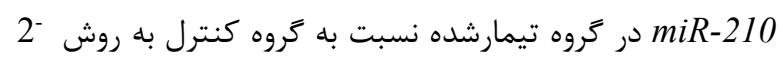
هACt

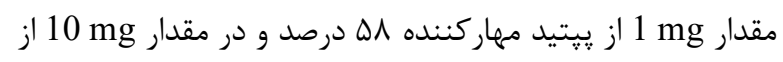

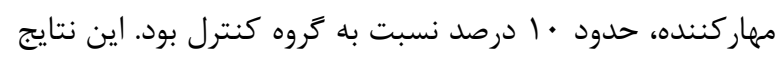
نشاندهنده كاهش بيان

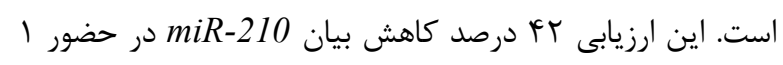

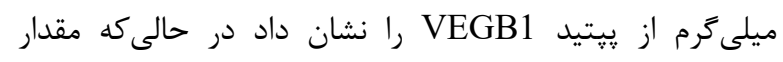

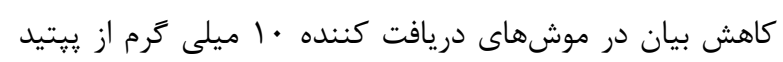

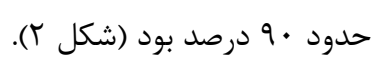

\section{بحث}

سرطان بستان بِيشرفته و متاستاتيك در حال حاضر غيرقابل

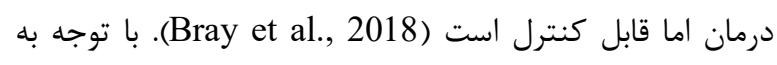

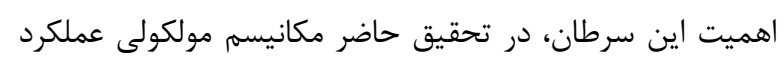

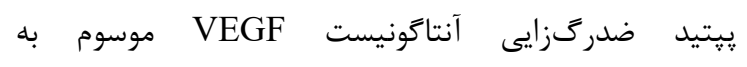

miR- و و تاثير آن بر بيان (Assareh et al., 2019)VEGB1 210 در موش هاى القا شده با تومور پستان مورد مطالعه قرار كرفت. اين پِيتيد به هر دو نوع كيرنده

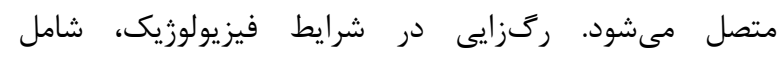
تشكيل كنترل شده عروق خونى از عروق موجود است. اين فرايند پِايه

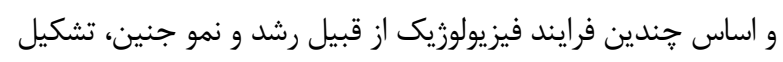

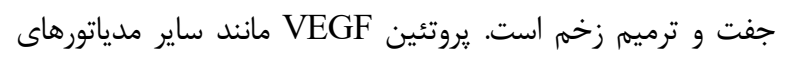

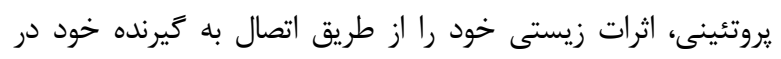

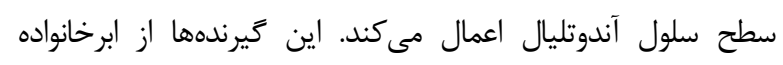

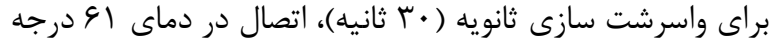

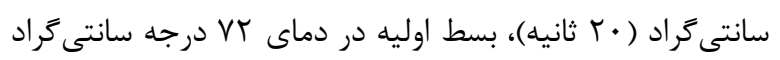

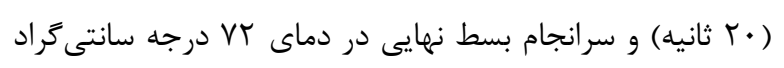

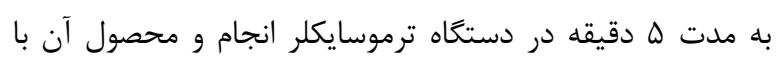

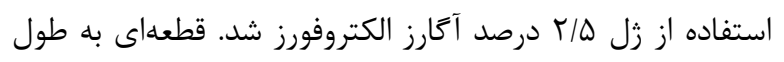

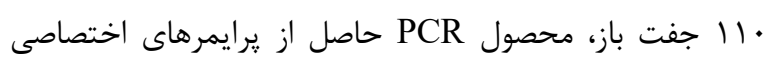

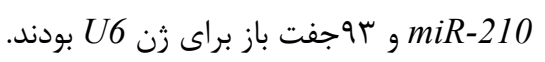

واكنش Real Time PCR

به منظور بررسى بيان زن

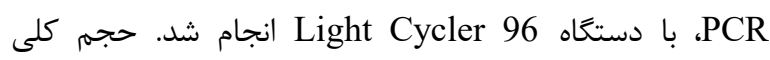

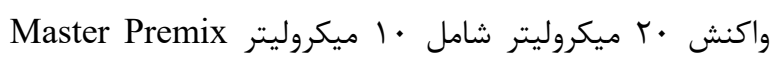

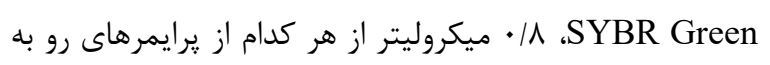

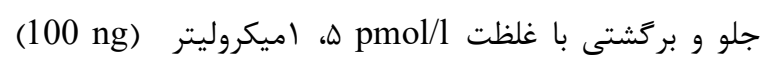
V/F , cDNA دمايى واسرشتسازى اوليه

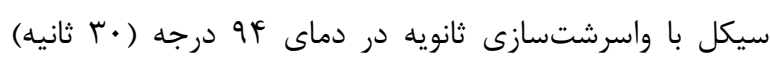

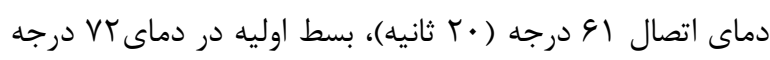

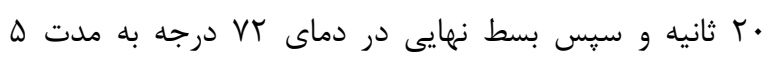

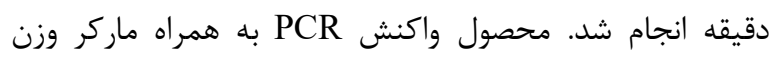

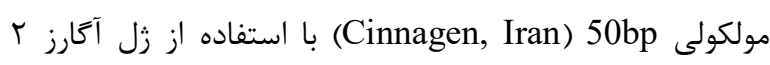

$$
\text { درصد الكتروفورز شد. }
$$

One-Sample براى سنجش نرمال بودن دادهها از آزمون Kolmogorov-Smirnov

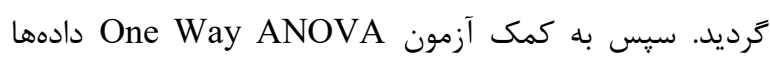

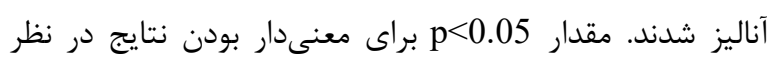

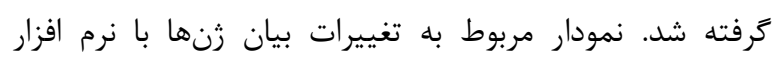
رسم كرديد و همجنين از روش

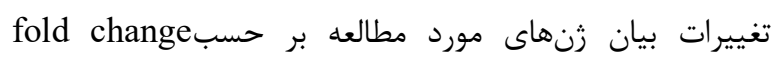
محاسبه شد.

\section{نتايج}

در اين تحقيق، براى بررسى تاثير ضدرگزايى يِّتيد آنتاكونيست VEGFB1 بر بيان

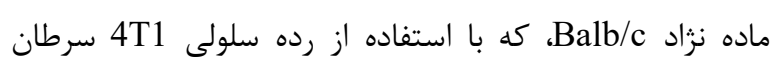

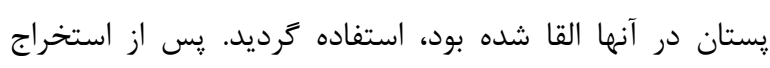
miRNA

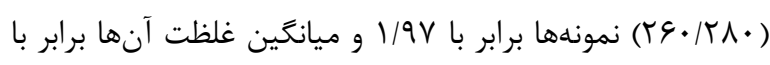

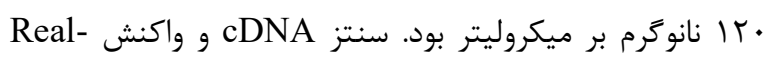
time PCR 
جدول ا- يرايمرهاى مورد استفاده در اين مطالعه.

Table 1- Used primers in this study

\begin{tabular}{cccc}
\hline Gene & Primer & Sequence & Tm $\left({ }^{\circ} \mathrm{C}\right)$ \\
\hline & Forward & 5'-CTGTGCGTGTGACAGCGGCTGA-3' & 67.7 \\
$m i R-210$ & Revers & 5'-GCGTCGACTAGTACAACTCAAG-3' & 62.1 \\
\hline \multirow{3}{*}{$U 6$} & Forward & 5'-GGTGGGAAGTGAGGGAGAGGG-3' & 67.2 \\
& Revers & 5'-GCGTCGACTAGTACACAAG-3' & 62.1 \\
\hline
\end{tabular}

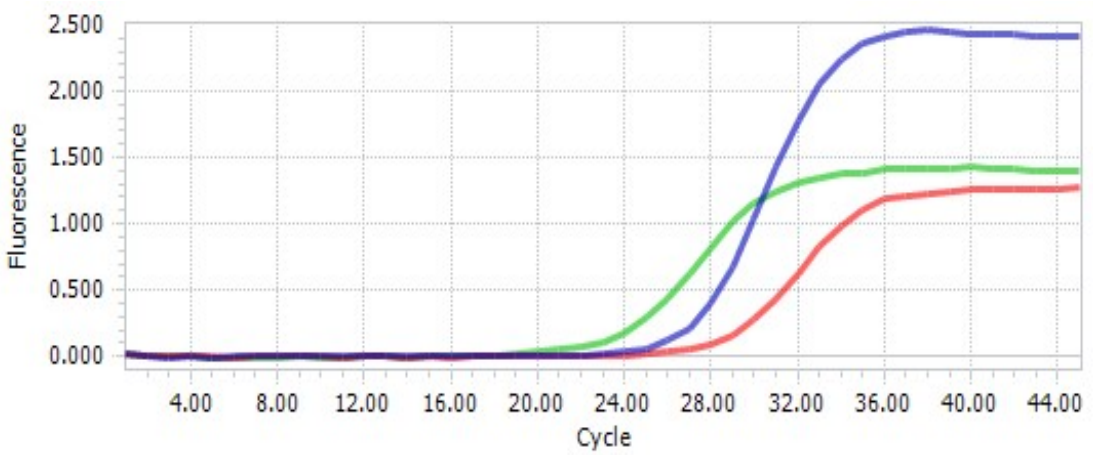

شكل ا- منحنى تكثير miR-210 در نمونهاى مورد مطالعه. سبز :كنترل. آبى: تيمار شده با 1 mg.kg-1 1 از VEGB1. قرمز: تيمار شده با 10 .VEGB1 ز $\mathrm{mg} \mathrm{kg}^{-1}$

Figure 1. Amplification curve of miR-210 in the studied samples: Green. Control. Blue. treated with $1 \mathrm{mg} \cdot \mathrm{kg}^{-1}$ of VEGB1. Red. treated with $10 \mathrm{mg} \mathrm{kg}^{-1}$ of VEGB1.

miRNA level expression (miR210/u6)

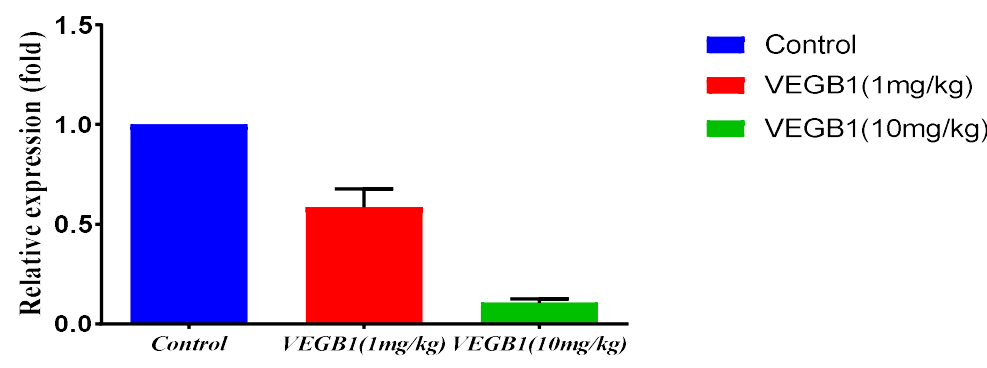

شكل r- اثر يِتيد مهار كننده رگزايى VEGB1 بر بيان

Figure 2. The effect of angiogenesis inhibitory peptide, VEGB1, on miR-210 expression in tumoral tissue relative to the contrl group.

كيرندهاى تيروزين كينازى هستند و تمامى ها ها شديدا هاى فاكتور رشد آندوتليال عروق نوع ا و † بهطور موثرى در سركوب

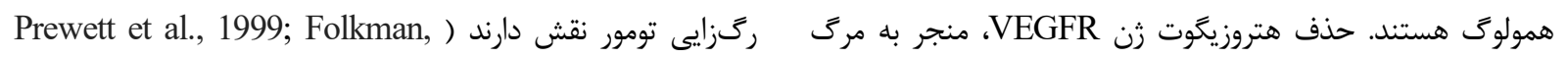

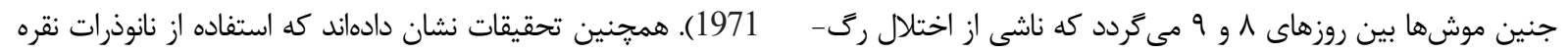

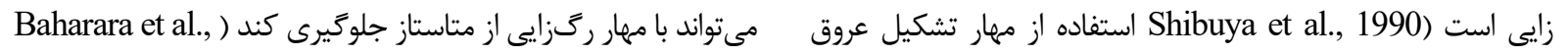

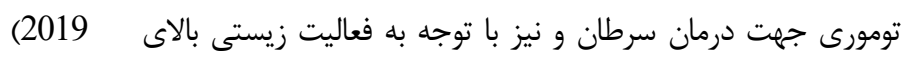
مداخله در مسيرهاى سيخنالينگ VEGFs يك استراترى مهم در

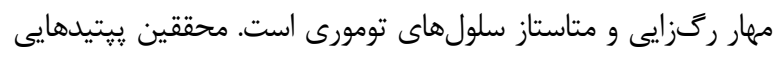
با قابليت اتصال به هر دو كيرنده، VEGFR-1 و VEFR-2

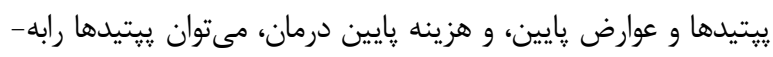

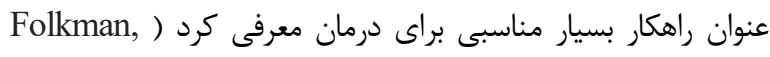

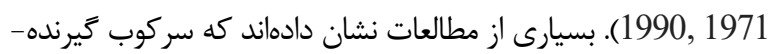




\section{REFERENCES}

Aliati, M.A., Ishikawa, M., Masuda, H., Simon, D.I., Jian, M.K., Asahra, T. \& Costa, M.A. 2012. Upregulation of miR-210 by vascular endothelial growth factor in ex vivo expanded CD34+ cells enhances cell-mediated angiogenesis. Journal of Cellular and Molecular Medicine 16: 2413- 2421.

Almeida, M. I., Reis, R. M. \& Calin, G. A. 2011. MicroRNA history: discovery, recent applications, and next frontiers. Mutation Research/Fundamental and Molecular Mechanisms of Mutagenesis 717: 1-8.

Assareh, E., Mehrnejad, F., Mansouri, K., Esmaeili Rastaghi, A.R., Naderi-Manesh, H. \& Asghari, S.M. 2019. A cyclic peptide reproducing the $\alpha 1$ helix of VEGF-B binds to VEGFR-1 and VEGFR-2 and inhibits angiogenesis and tumor growth. Biochemical Journal 476: 645-663.

Baharara, J., Zafar-Balanejad, S., NejadShahrokhabadi, K. \& Hesami, Z. 2012. The effects of different doses of atorvastatin on angiogenesis of chorioallantoic membrane of chick embryo. Journal of Shahrekord University of Medical Sciences 14: 82-89.

Baharara, J., Ramezani, T., Saghiri, N. \& Salek, F. 2019. Investigating the apoptotic effects of silver nanoparticles coated with Achillea biebersteinii extract on A2780 ovarian cancer cells. Nova Biologica Reperta 6: 140-147. (In Persian).

Bauer, S.M., Bauer, R.J. \& Velazquez, O.C. 2005. Angiogenesis, vasculogenesis, and induction of healing in chronic wounds. Vascular and Endovascular Surgery 39: 293-306.

Bavelloni, A., Ramazzotti, G., Poli, A., Piazzi, M., Focaccia, E., Balalock, W. \& Faenza, I. 2017. MiRNA-210: A Current Overview. Anticancer Research 37: 6511-6521.

Bianchi, N., Zuccato, C., Lampronti, I., Borgatti, M. \& Gambari, R. 2009. Expression of miR-210 during erythroid differentiation and induction of gammaglobin gene expression. BMB Reports 42: 493-499.

Bray, F., Ferlay, J., Soerjomataram, I., Siegel, R. L., Torre, L.A. \& Jemal, A. 2018. Global cancer statistics 2018: GLOBOCAN estimates of incidence and mortality worldwide for 36 cancers in 185 countries. CA: a Cancer Journal for Clinicians 68 : 394-424.

Carmeliet, P. \& Jain, R.K. 2011. Molecular mechanisms and clinical applications of angiogenesis. Nature 473: 298-307.

Carramolino, L., Fuentes, J., García-Andrés, C., Azcoitia, V., Riethmacher, D. \& Torres, M. 2010.

Platelets play an essential role in separating the blood and lymphatic vasculatures during embryonic angiogenesis. Circulation Research 106: 1197-201

Desantis, C., Siegel, R., Bandi, P. \& Jemal, A. 2011. Breast cancer statistics, 2011. CA: a Cancer Journal for Clinicians 61: 408-418.

Egginton, S. 2009. Invited review: activity-induced angiogenesis. Pflügers Archiv-European Journal of Physiology 457: 963-977.
طراحى كرده و نشان دادند كه اين يِتيدها مىتوانند در مهار رگزايى

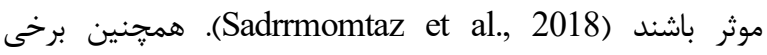

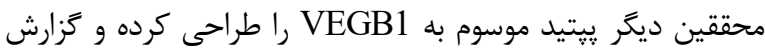

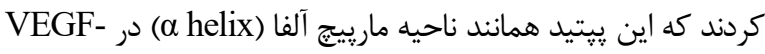

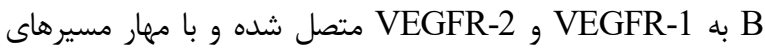
سيخنالينَ PI3/AKT و MAPK/ERK 1/2 به از تكثير و متاستاز

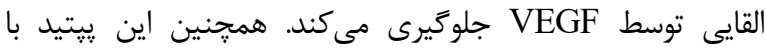
ممانعت از تشكيل عروق كوجك مانع رشد تومورهاى يستانى

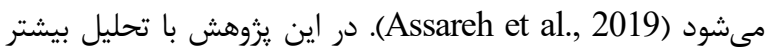
نتايج حاصل از بيان miR-210 تحت اثر بيتيد ضدرگزايى ANOVA 1 (VEGB1)

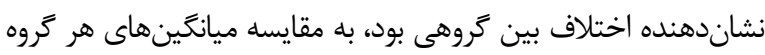
باهم يرداخته شد. نتايج حاصل از آزمونهاى آمارى بيانكر بيشترين

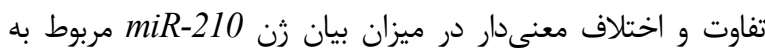

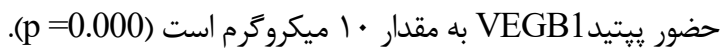
نتايج اين تحقيق در مطابقت با نتايج تحقيقات ديگر مبنى بر ارتباط مستقيم MEGF و MiR-210 در رگزايى هستند. تحقيقات نشان داده است در سلولهاى

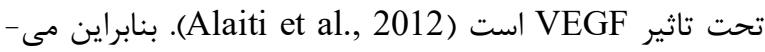
توان گفت با مسدود شدن گيرندههاى VEGF، بيان miR نيز كاهش مىيابد. گزارش شده است كه افزايش

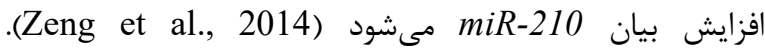
همجنين، تحقيقات نشان دادهاند كه در فرايند رگزايى در

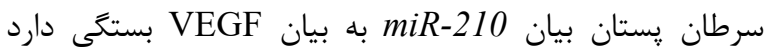

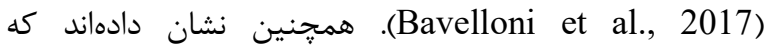
هييوكسى باعث افزايش بيان VEGF شده و در نتيجه بيان 210-

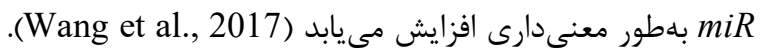

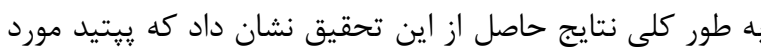

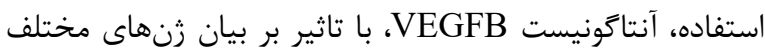
موثر در رگزايى، اين فرايند را كاهش مىدهد. بنابراين علاوهبر

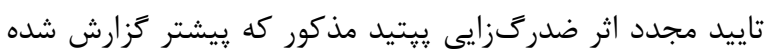
بود، نشان داده شد كه يكى از مكانيسمهاى عملكرد آن تاثير

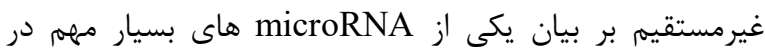
رىزايى يعنى

$$
\text { سياسگزارى }
$$

بدينوسيله از دانشكده علوم يايه دانشگاه گَيلان و خانم لاله

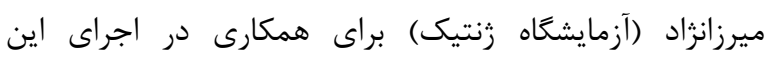
يزوهش قدردانى مىشود. 
Folkman, J. 1990. What is the evidence that tumors are angiogenesis dependent? Journal of the National Cancer Institute 82: 4-7.

Folkman, J., 1971. Tumor angiogenesis: therapeutic implications. New England Journal of Medicine 285: 1182-1186.

Fukasawa, M., Matsushita, A. \& Korc, M. 2007. Neuropilin-1 interacts with integrin $\beta 1$ and modulates pancreatic cancer cell growth, survival and invasion. Cancer Biology \& Therapy 6: 1184-1191.

Kamat, A., Rajoria, S., George, A., Suriano, R., Shanmugam, A., Megwalu, U., Prakash, P.B., Tiwari, R. \& Schantz, S. 2011. Estrogen-mediated angiogenesis in thyroid tumor microenvironment is mediated through VEGF signaling pathways. Archives of Otolaryngology-Head \& Neck Surgery 137: 1146-1153.

Kerbel, R. S. 2000. Tumor angiogenesis: past, present and the near future. Carcinogenesis 21: 505-515.

Kolahdoozan, S., Sadjadi, A., Radmard, A.R. \& Khademi, H. 2010. Five common cancers in Iran. Archives of Iranian Medicine 13: 143-146.

Leung, D.W., Cachianes, G., Kuang, W.J., Goeddel, D.V. \& Ferrara, N. 1989. Vascular endothelial growth factor is a secreted angiogenic mitogen. Science 246: 1306-1309.

Meimandi, K. \& Yaghoobi, M.M. 2019. The effect of aqueous and ethanolic extracts of Sedum album L. on human stomach and breast carcinoma cell lines in vitro. Nova Biologica Reperta 6: 10-19. (In Persian).

Noroozi, A., Jomand, T. \& Tahmasebi, R. 2011. Determinants of breast self-examination performance among Iranian women: an application of the health belief model. Journal of Cancer Education 26: 365374.

Odorisio, T., Cianfarani, F., Failla, C.M. \& Zambruno, G. 2006. The placenta growth factor in skin angiogenesis. Journal of Dermatological Science 41: 11-19.

Prewett, M., Huber, J., Li, Y., Santiago, A., O'Connor, W., King, K., Overholser, J., Hooper, A., Pytowski, B., Witte, L. \& Bohlen, P. 1999.
Antivascular endothelial growth factor receptor (fetal liver kinase 1) monoclonal antibody inhibits tumor angiogenesis and growth of several mouse and human tumors. Cancer Research 59: 5209-5218.

Ramezani., S., Talesh Sasani, S., Fakor, F. \& Alizadehsefat, S. 2020. Relationship of the expression of circulating hsa-miR-125a-3p and hsamiR125b with breast cancer. British Journal of Biomedical Science 77: 41-43.

Sadremomtaz, A., Kobarfard, F., Mansouri, K., Mirzanejad, L. \& Asghari, S.M. 2018. Suppression Of migratory and metastatic pathways via blocking VEGFR1 and VEGFR2. Journal of Receptors and Signal Transduction 38: 432-441.

Sempere, L.F. \& Kauppinen, S. 2009. Translational implications of microRNAs in clinical diagnostics and therapeutics. Handbook of Cell Signaling ( $2^{\text {nd }}$ ed.). Elsevier.

Shibuya, M., Yamaguchi, S., Yamane, A., Ikeda, T., Tojo, A., Matsushime, H. \& Sato, M.J.O. 1990. Nucleotide sequence and expression of a novel human receptor-type tyrosine kinase gene (flt) closely related to the fms family. Oncogene 5: 519-524.

Smith, R.A., Andrews, K. S., Brooks, D., Fedewa, S.A., Manassaram-Baptiste, D., Saslow, D., Brawley, O.W. \& Wender, R.C. 2017. Cancer screening in the United States: a review of current American Cancer Society guidelines and current issues in cancer screening. CA: a Cancer Journal for Clinicians 67: 100-121.

Stewart, B. \& Wild, C.P. 2014. World cancer repot. World Health Organization, Geneva.

Wang, Z., Deng, M., Liu, Z. \& Wu, S. 2017. Hypoxiainduced miR-210 promoter demethylation enhances proliferation, autophagy and angiogenesis of schwannoma cells. Oncology Reports 37: 3010-3018.

Zeng, L., He, X., Wang, Y., Tang, Y., Zheng, C., Cai1, H., Liu, J., Wang, Y., Fu, Y. \& Yang, G-Y. 2014. MicroRNA-210 overexpression induces angiogenesis and neurogenesis in the normal adult mouse Brain. Gene Therapy 21: 37-43.

How to cite this article:

Kaboudan, F., Talesh Sasani,S. \& Asghari, S.A. 2021. The effect of a VEGFB antagonist peptide on miR-210 expression level in breast cancer in a mouse model. Nova Biologica Reperta 8: 13-19. (In Persian).

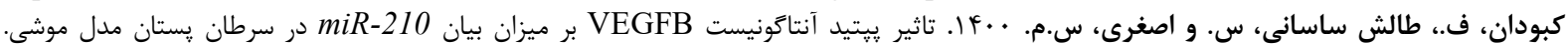

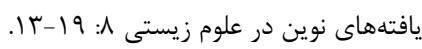

